\title{
Factors influencing asthma control: results of a real-life prospective observational asthma inhaler treatment (ASIT) study
}

This article was published in the following Dove Press journal:

Journal of Asthma and Allergy

29 June 2013

Number of times this article has been viewed

Füsun Yıldız

\section{On behalf of the ASIT Study Group}

Department of Pulmonary Disease, Kocaeli University School of Medicine, Kocaeli, Turkey
Correspondence: Füsun Yıldız Kocaeli Universitesi Tıp Fakültesi Göğüs Hastalıkları Anabilim Dalı, Umuttepe Merkez Yerleșkesi, 4I380, Kocaeli, Turkey

Tel +902623037513

Fax +902623037003

Email fusun.yildiz@gmail.com
Background: Despite the availability of new pharmacological options and novel combinations of existing drug therapies, the rate of suboptimal asthma control is still high. Therefore, early identification of the clinical and behavioral factors responsible for poor asthma control, and interventions during routine outpatient visits to improve asthma trigger management, are strongly recommended. This study was designed to evaluate the profiles of asthmatic patients and their inhaler treatment devices in relation to asthma control in Turkey.

Methods: A total of 572 patients with persistent asthma (mean [standard deviation] age: 42.7 [12.1] years; $76 \%$ female) were included in this prospective observational study. A baseline visit ( 0 month, visit 1$)$ and three follow-up visits (1, 3 and 6 months after enrolment) were conducted to collect data on demographics, past medical and asthma history, and inhaler device use.

Results: Asthma control was identified in $61.5 \%$ of patients at visit 1 and increased to $87.3 \%$ at visit $4(P<0.001)$, regardless of sociodemographics, asthma duration, body mass index or smoking status. The presence of asthma-related comorbidity had a significantly negative effect on asthma control $(P=0.004)$. A significant decrease was determined, in the rate of uncontrolled asthma, upon follow-up among patients who were using a variety of fixed dose combination inhalers $(P<0.001$ for each). Logistic regression analysis was used to show that the presence of asthma-related comorbidity (odds ratio [OR], 0.602; 95\% confidence interval [CI], 0.419; $0.863, P=0.006)$ and active smoking (OR, $0.522 ; 95 \% \mathrm{CI}, 0.330 ; 0.825, P=0.005)$ were significant predictors of asthma control.

Conclusion: Our findings indicate that, despite ongoing treatment, asthma control rate was $61.5 \%$ at visit 1 in adult outpatients with persistent asthma. However, by the final follow-up 6 months later, this had increased to $87.3 \%$, independent of sociodemographic and clinical characteristics. Poor asthma control was associated with asthma-related comorbid diseases, while the efficacy of fixed dose combinations was evident in the achievement of asthma control.

Keywords: persistent asthma, patient profile, asthma control, inhaler treatment, adults, Turkey

\section{Introduction}

As a common chronic disease that substantially burdens both patients' lives and health economics, ${ }^{1,2}$ asthma has 300 million sufferers worldwide, with an additional 100 million people estimated to be affected by $2025 .^{3}$ The number of patients diagnosed with asthma in Turkey was estimated at 3-4 million, ${ }^{4}$ while the prevalence proportion was reported at $7.4 \%$ by the Global Initiative for Asthma (GINA) - Global Burden of Asthma Report. ${ }^{5}$ 
Although the results of clinical trials suggest that asthma control can be reached in most patients, ${ }^{6}$ the epidemiologic evidence suggests a low level of disease control in many countries including Turkey, ${ }^{7-9}$ despite the availability of international and national asthma guidelines, and effective medications that would enable optimum control of the disease. ${ }^{5,10}$

Therefore, the challenge to find the best way to assess asthma control and define management strategies to ensure that this control is achieved and maintained, still remains. ${ }^{11}$ The update of the GINA 2006 guidelines recommends a newly introduced asthma management approach, based on the monitoring of disease control, to facilitate the acceptance and use of asthma guidelines in clinical practice. ${ }^{5}$ This approach is based on the use of combined therapies in which inhaled corticosteroids (ICS) are given, mainly in combination with long-acting beta-2-adrenoceptor agonists (LABA). ${ }^{12-14}$ However, despite this availability of new pharmacological options and novel combinations of existing drug therapies, suboptimal asthma control rates are persistently high. ${ }^{15}$

In order to tackle this, early identification of the clinical and behavioral factors responsible for poor asthma control, ${ }^{16}$ and interventions during routine outpatient visits for improving asthma trigger management, ${ }^{17}$ have been recommended. In addition, follow-up consultations including checking the patients' adherence to their medication plan, and measures to reduce the exposure to risk factors have also been strongly recommended. ${ }^{18}$

Clinicians and general practitioners must be aware of the levels and determinants of asthma control in order to reflect and improve on the implementation of the asthma guidelines. ${ }^{5,19}$ Therefore this real-life prospective ASIT (Asthma Inhaler Treatment) study, conducted at 31 secondary and tertiary centers across Turkey, was designed to evaluate the profiles of persistent-asthma patients and their inhaler treatment devices in relation to asthma control, through a series of follow-ups.

\section{Material and Methods Study population}

A total of 572 patients with persistent asthma were included in this multi-center, non-interventional, single arm prospective observational study, conducted at 31 pneumology outpatient clinics across Turkey. The study was based on four consecutive visits, the first performed at the study enrolment (month 0, visit 1), and then follow-ups at 1,3, and 6 months. Female or male outpatients older than 18 years and diagnosed with persistent asthma according to the GINA criteria ${ }^{12}$ at least 6 months previously, and who had received at least one dose of ICS + LABA either in separate or fixed combinations irrespective of pharmacological agent(s), were included. The exclusion criteria were: confirmed or suspected pregnancy; breastfeeding; comorbid COPD; allergy/sensitivity or intolerance to any kind of asthma treatment; anti-immunoglobulin $\mathrm{E}$ treatment within the last 4 months; treatment with leukotriene receptor antagonists; hospitalization due to symptomatic respiratory infection of asthma within the last 8 weeks; chronic diseases that were likely to negatively affect the prognosis (eg, carcinoma); chronic alcohol consumption; and substance abuse.

Following detailed explanation of the objectives and protocol of the study, written informed consent was obtained from each subject. The study was conducted in accordance with the ethical principles stated in the "Declaration of Helsinki" and approved by the Kocaeli University Research Ethics Committee.

\section{Data collection}

After certifying the patients' eligibility against the inclusion/ exclusion criteria, data on sociodemographic characteristics (age, gender, educational status, and occupation), vital signs, physical examination findings, medical history, comorbid disorders, concomitant treatments, characteristics and clinical course of asthma disease, asthma control, and asthma treatment via inhaler device were collected at the initial enrollment visit. At each follow up visit, patients were evaluated for vital signs, physical examination findings, concomitant treatments, characteristics and clinical course of asthma disease, asthma control, and asthma treatment via inhaler device.

The Asthma Control Test (ACT), a standard test developed for reflecting the patient's perspective of his/her disease, ${ }^{20}$ helps determine asthma control levels, predict exacerbations, and optimize therapy for the patients. ${ }^{21,22}$ The ACT ${ }^{\mathrm{TM}}$ has been translated into Turkish and cultural adaptation has been completed. ${ }^{23}$

In the present study, the $\mathrm{ACT}^{\mathrm{TM}}$ filled in by patients was used to assess their level of asthma control in the 4 weeks preceding the enrollment, considering an overall score of 20 or higher as controlled asthma, and a score less than 20 as uncontrolled asthma.

\section{Statistical analysis}

Sample size was calculated to include at least 1050 patients to be able to observe $40 \%$ of the difference between two different treatment alternatives or inhaler devices and standard 
error of $2 \%$, confidence level of $>95 \%$, and statistical power of $90 \%$. However, only 572 patients were enrolled in the study.

Stata Data Analysis and Statistical Software (Version 10, StataCorp LP, College Station, TX, USA) was used for statistical analysis. Data were expressed as "mean (standard deviation [SD])", percent (\%) and 95\% confidence interval where appropriate. Significance levels during the categorical comparison of the groups were evaluated by the Chi-square test using cross table statistics. The Kruskal-Wallis and Mann-Whitney U tests were used for independent groups without normal distribution, while Student's $t$-test was used for comparison of two independent groups. The ANOVA test and post-hoc Tukey's HSD test were used for more than two independent groups with normal distribution. Logistic regression analysis was performed with asthma control (categorical) as the dependent variable while "Enter" was selected as the method and "simple first" as the categorical variable coding scheme. Predictors with possible influence on dependent variable were added as covariates. All tests were two-sided and $P<0.05$ was considered statistically significant.

\section{Results}

\section{Baseline demographic, clinical and asthma-related characteristics}

The mean (SD) age of the 572 patients in the ASIT study was $42.7(12.1)$ years and $76 \%(n=435)$ were females. The majority of the patients $(n=440 ; 76.9 \%)$ were secondary school graduates and $61.9 \%$ were unemployed $(55.8 \%$ housewives) (Table 1). Mean (SD) time from asthma onset was 8.0 (8.3) years while less than or equal to 5 years in $53.3 \%$ of the patients (Table 1). Active smokers represented $18.2 \%(n=104)$ of the patients (Table 1$)$.

Among the 530 patients with comorbidities, 56.1\% $(\mathrm{n}=321)$ had asthma-related disorders, and a single asthmarelated comorbidity was noted in $67.9 \%$ of the patients (Table 1).

The evaluation of vital signs showed mean (SD) systolic blood pressure (BP) as 121.1 (15.6) $\mathrm{mmHg}$, diastolic BP as $75.6(8.9) \mathrm{mmHg}$, pulse as $81.2(8.9) / \mathrm{min}$, and respiratory rate as $16.8(3.2) / \mathrm{min}$. Mean (SD) body mass index (BMI) was $28.0(5.4)\left(\mathrm{kg} / \mathrm{m}^{2}\right)$.

\section{Baseline characteristics associated with asthma control status}

Overall, asthma was determined to be controlled in $61.5 \%(n=352)$ of the patients, with no statistical difference in control level with respect to mean age, gender, asthma duration, educational, or employment status. The uncontrolled asthma group had a significantly higher number of active smokers $(23.2 \%)$ versus $15.1 \%$ in the controlled asthma group $(P=0.015)$ (Table 1$)$.

The presence of asthma-related comorbidities had significantly negative effects on asthma control (Table 1). Half $(51.4 \%)$ of the patients with controlled asthma had asthmarelated comorbidities, while this percentage rose to $63.6 \%$ $(140 / 220)$ in the uncontrolled asthma group $(P=0.004)$. The most common asthma-related comorbidity was rhinitis, and this was significantly more frequent among uncontrolled asthma group $(P=0.009)$.

\section{Asthma control status throughout the study visits}

Overall, the ratio of patients with controlled asthma was significantly higher $(61.5 \%$ at visit $1,82.0 \%$ at visit $2,84.8 \%$ at visit 3 and $87.3 \%$ at visit $4 ; P<0.001$ for each) than that of uncontrolled asthma at each study visit and there was a significant progressive decrease in the ratio of uncontrolled patients at the follow-up visits compared to baseline ( $P<0.001$ for each) from $38.5 \%$ to $12.7 \%$ at the end of the study (Figure 1 ).

\section{Asthma control status from visit I to visit 4: asthma duration, BMI, smoking status and comorbid disorders}

When asthma control status from visit 1 to visit 4 was evaluated in terms of time from asthma onset (0-15 versus more than 15 years), BMI (30 kg/m² or higher versus less than $30 \mathrm{~kg} / \mathrm{m}^{2}$ ), and smoking status (smoker versus nonsmoker), a significant decrease in the ratio of patients with uncontrolled asthma was found in each case, regardless of the grouping (Table 2). Significantly higher rates of asthma control at visit 4 compared to visit 1 were detected even in patients with time from asthma onset more than 15 years (Table 2). On the other hand, the asthma control rate was significantly higher at all visits, both among nonsmokers compared to active smokers (64\% versus 51\%, $P=0.010$ and $89 \%$ versus $78 \% ; P=0.030$, respectively); and among patients with BMI lower than $30 \mathrm{~kg} / \mathrm{m}^{2}$ compared to those with BMI $30 \mathrm{~kg} / \mathrm{m}^{2}$ or higher at visit $4(88.5 \%$ versus $81.8 \%$, $P=0.009$ ) (Table 2).

Patients with one $(P<0.001)$, two $(P=0.004)$ and three $(P=0.021)$ comorbidities had significantly higher ACT scores at visit 4 compared to visit 1 , while baseline ACT scores of patients with three comorbidities were significantly lower than baseline scores of patients with a single comorbidity $(P=0.007)$ (Table 2$)$. 
Table I Sociodemographic characteristics of patients according to asthma control at baseline

\begin{tabular}{|c|c|c|c|c|}
\hline & \multirow[t]{2}{*}{ Overall $(n=572)$} & \multicolumn{2}{|l|}{ Asthma control status } & \multirow[t]{2}{*}{$P$ value } \\
\hline & & $\begin{array}{l}\text { Controlled } \\
(\mathrm{ACT} \geq 20, \mathrm{n}=352)\end{array}$ & $\begin{array}{l}\text { Uncontrolled } \\
(A C T<20, n=220)\end{array}$ & \\
\hline \multicolumn{5}{|c|}{ Mean (SD) } \\
\hline Age (year) & $42.7(12.2)$ & $43.6(12.1)$ & $41.3(12.2)$ & 0.061 \\
\hline Age categories (year) & n (\%) & & & \\
\hline $18-40$ & $252(44.1)$ & I44 (40.9) & $108(49.1)$ & 0.055 \\
\hline $4 I-60$ & $272(47.6)$ & $175(49.7)$ & $97(44.1)$ & 0.192 \\
\hline$>60$ & $48(8.4)$ & $33(9.4)$ & $15(6.8)$ & 0.276 \\
\hline Gender & n (\%) & & & \\
\hline Male & $137(24.0)$ & $92(26.1)$ & $45(20.5)$ & 0.127 \\
\hline Female & $435(76.0)$ & $260(73.9)$ & $175(79.5)$ & 0.127 \\
\hline \multicolumn{5}{|c|}{ Mean (SD) } \\
\hline Time from asthma onset (years) & $8.0(8.3)$ & $8.0(8.3)$ & $8.0(8.2)$ & 1.00 \\
\hline \multicolumn{5}{|c|}{ n (\%) } \\
\hline$\leq 5$ & $305(53.3)$ & $191(54.3)$ & I I 4 (5I.8) & 0.560 \\
\hline$>5$ to $\leq 10$ & II 8 (20.6) & $68(19.3)$ & $50(22.7)$ & 0.328 \\
\hline$>10$ to $\leq 15$ & $59(10.3)$ & $36(10.2)$ & $23(10.5)$ & 0.909 \\
\hline$>15$ & $90(15.7)$ & $57(16.2)$ & $33(15.0)$ & $0.70 \mathrm{I}$ \\
\hline Comorbidities & n (\%) & & & \\
\hline None & $162(28.3)$ & $115(32.7)$ & $47(21.4)$ & 0.003 \\
\hline Non-asthma related & $209(36.5)$ & $126(35.8)$ & $83(37.7)$ & 0.646 \\
\hline Asthma related & $32 I(56.1)$ & I8I (5I.4) & $140(63.6)$ & 0.004 \\
\hline Rhinitis* & $219(68.2)$ & $120(66.3)$ & $99(70.7)$ & 0.009 \\
\hline Sinusitis* & $105(32.7)$ & $57(31.5)$ & $48(34.3)$ & 0.092 \\
\hline GERD* & $106(33.0)$ & $59(32.6)$ & $47(33.6)$ & 0.169 \\
\hline \multicolumn{5}{|l|}{ Number of comorbidities } \\
\hline I comorbidity & $218(67.9)$ & $109(31)$ & $109(62.5)$ & $<0.001$ \\
\hline 2 comorbidities & $69(21.5)$ & $35(9.9)$ & $34(15.5)$ & 0.045 \\
\hline 3 comorbidities & $34(10.6)$ & $19(5.4)$ & $15(6.8)$ & 0.491 \\
\hline Active smoking & $104(18.2)$ & $53(15.1)$ & $5 \mathrm{I}(23.2)$ & 0.015 \\
\hline \multicolumn{5}{|l|}{ Educational status } \\
\hline Illiterate & $28(4.9)$ & $14(4.0)$ & $14(6.4)$ & 0.197 \\
\hline Secondary school & $440(76.9)$ & $279(79.3)$ & $161(73.2)$ & 0.092 \\
\hline University & $104(18.2)$ & $59(16.8)$ & $48(21.8)$ & 0.139 \\
\hline Employment status & n (\%) & & & \\
\hline Unemployed & $354(61.9)$ & $223(63.4)$ & $|3|(59.5)$ & 0.350 \\
\hline Employed & $210(36.7)$ & $126(35.8)$ & $84(38.2)$ & 0.562 \\
\hline Missing & 8 & 3 & 5 & \\
\hline
\end{tabular}

Note: *Percent of patients with asthma-related comorbidities.

Abbreviation: ACT, asthma control test; $n$, number; SD, standard deviation.

\section{Asthma control status from visit I to visit 4: inhaler treatment}

Significant improvement in asthma control status during follow-up was observed in patients using fixed dose ICS/ LABA combination inhalers (Table 3). There was a significant decrease in the ratio of patients with uncontrolled asthma from visit 1 to visit 4 for patients who received: 'fluticasone propionate/salmeterol discus' (38.2\% versus $11.4 \%$, $P<0.001)$; 'extra fine beclomethasone/formoterol solution spray' $(32.7 \%$ versus $10.0 \%, P<0.001)$; and 'budesonide/ formoterol turbuhaler' $(41.7 \%$ to $14.9 \%, P<0.001)$. There were no significant changes in the ratio of uncontrolled asthma observed in patients receiving 'budesonide and formoterol aerolizer' $(42.9 \%$ to $23.5 \%, P=0.131$ ) (Table 3 ). Overall, the ratio of patients with uncontrolled asthma was decreased by $45.2 \%-70.2 \%$, depending on the inhaler type (Figure 2).

\section{Logistic regression analysis for predictors of asthma control}

Using asthma control (categorical) as the dependent variable, logistic regression analysis showed that the presence of asthma-related comorbidity (odds ratio [OR], 0.602; 95\% CI, 0.419;0.863, $P=0.006)$ and active smoking (OR, 0.522; 


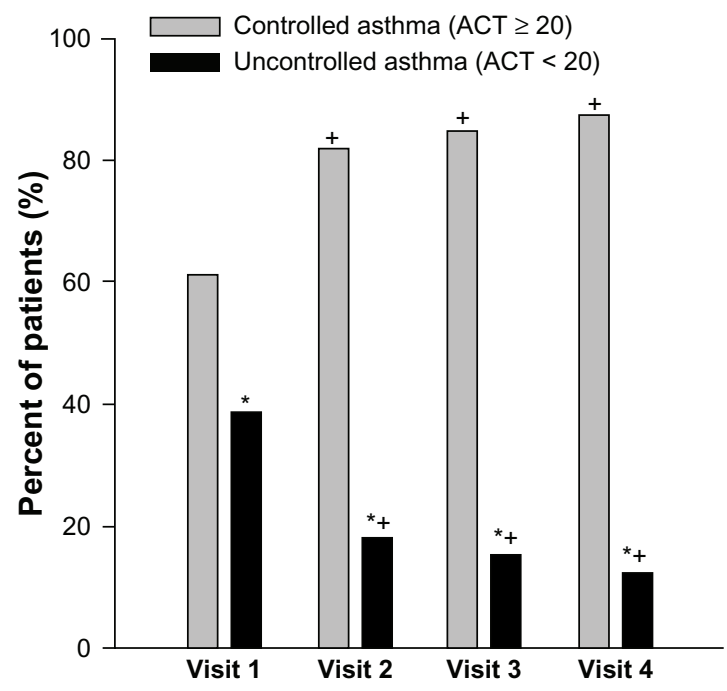

Figure I Asthma control improvement between visits.

Note: ${ }^{*} P<0.00$ I, compared to rate of controlled asthma at the same visit; ${ }^{+} P<0.00$ I compared to visit I.

Abbreviation: ACT, asthma control test.

95\% CI, 0.330; $0.825, P=0.005)$ were significant predictors of asthma control (Table 4).

\section{Discussion}

The principal findings of this real-life prospective ASIT study showed that the asthma control rate increased during follow up in adult outpatients with persistent asthma, moving from $61.5 \%$ to $87.0 \%$ after 6 months, regardless of patient demographics, smoking, educational, or employment status. Notably, the incidence of comorbid diseases was associated with poor asthma control, while fixed dose combinations proved highly effective in asthma control.

Failure in asthma control has been reported in several studies, despite variations in selected populations and methodology, ${ }^{19}$ while objectives for good control proposed by international reference guidelines are still far from being met. ${ }^{7,24-26}$ National and international asthma management guidelines recommend continuous, preventive rather than symptom-driven and crisis-oriented care..$^{27,28}$ In this regard, justifying emphasis on asthma control versus asthma severity in the guidelines, our finding of asthma control (ACT score of $\geq 20$ ) in $87.3 \%$ of patients promisingly highlights the role of patient monitoring via close follow up in the achievement of better asthma control.

The Asthma Insights and Reality in Europe (AIRE) Study, a multinational, population-based telephone survey, showed that $94.7 \%$ of all patients fail to achieve proper control of their disease. ${ }^{24}$ The ASES Study, an office-based study conducted in Spain, confirmed that the percentage of patients at primary care and pneumologist office visits who

Table 2 Change in asthma control status from Visit I-Visit 4 in terms of asthma duration, BMI, smoking status, and comorbid disorders

\begin{tabular}{|c|c|c|c|c|c|c|}
\hline & \multicolumn{6}{|c|}{ Asthma control status } \\
\hline & \multicolumn{3}{|c|}{ Controlled $(\mathrm{ACT} \geq 20)$} & \multicolumn{3}{|c|}{ Uncontrolled $(\mathrm{ACT}<20)$} \\
\hline & $\begin{array}{l}\text { Visit I } \\
\text { n (\%) }\end{array}$ & $\begin{array}{l}\text { Visit } 4 \\
\text { n (\%) }\end{array}$ & $P$ value* & $\begin{array}{l}\text { Visit I } \\
\text { n (\%) }\end{array}$ & $\begin{array}{l}\text { Visit } 4 \\
\text { n (\%) }\end{array}$ & $P$ value* \\
\hline All patients & $352(61.5)$ & $269(87.3)$ & $<0.00 \mathrm{I}$ & $220(38.5)$ & $39(12.7)$ & $<0.001$ \\
\hline \multicolumn{7}{|l|}{ Time from asthma onset (years) ${ }^{a}$} \\
\hline $0-15$ years $(\mathrm{VI}: \mathrm{n}=482 ; \mathrm{V} 4: \mathrm{n}=25 \mathrm{I})$ & $294(61.0)$ & $215(86.0)$ & $<0.001$ & $187(39.0)$ & $35(14.0)$ & $<0.001$ \\
\hline$\geq 15$ years $(\mathrm{VI}: \mathrm{n}=90 ; \mathrm{V} 4: \mathrm{n}=57)$ & $57(63.0)$ & $52(91.0)$ & $<0.001$ & $33(37.0)$ & $4(9.0)$ & $<0.001$ \\
\hline \multicolumn{7}{|l|}{ BMI $\left(\mathrm{kg} / \mathrm{m}^{2}\right)^{\mathrm{b}}$} \\
\hline$\geq 30(\mathrm{VI}: \mathrm{n}=180 ; \mathrm{V} 4: \mathrm{n}=88)$ & $107(59.4)$ & $72(81.8)$ & 0.0003 & $73(40.6)$ & $16(18.2)$ & $<0.001$ \\
\hline$<30(V|: n=363 ; \mathrm{V} 4: \mathrm{n}=| 3 \mid)$ & $226(62.3)$ & 116 (88.5) & $<0.001$ & $137(37.7)$ & I5 (II.5) & $<0.001$ \\
\hline \multicolumn{7}{|l|}{ Smoking ${ }^{c}$} \\
\hline Smoker (VI: $\mathrm{n}=104 ; \mathrm{V} 4: \mathrm{n}=50)$ & $52(51.0)$ & $39(78.0)$ & 0.0014 & $51(49.0)$ & II (22.0) & 0.001 \\
\hline Non-smoker (VI: $\mathrm{n}=468 ; \mathrm{V} 4: \mathrm{n}=258)$ & $300(64.0)$ & $230(89.0)$ & $<0.001$ & $168(36.0)$ & $28(11.0)$ & $<0.001$ \\
\hline \multirow[t]{3}{*}{ Comorbid disorder \# } & \multicolumn{3}{|l|}{ ACT score } & & \multirow[t]{3}{*}{$P$ value** } & \\
\hline & Visit I & & Visit 4 & & & \\
\hline & Mean (SD) & & Mean (SD) & & & \\
\hline I (VI: $n=218 ; V 4: n=117)$ & $19.9(4.4)$ & & $22.6(3.3)$ & & $<0.001$ & \\
\hline $2(\mathrm{VI}: \mathrm{n}=69 ; \mathrm{V} 4: \mathrm{n}=33)$ & $19.3(4.7)$ & & $22.0(4.1)$ & & 0.004 & \\
\hline $3(\mathrm{VI}: \mathrm{n}=34 ; \mathrm{V} 4: \mathrm{n}=20)$ & $16.9(6.1)^{* *}$ & & $20.4(4.6)$ & & 0.021 & \\
\hline
\end{tabular}

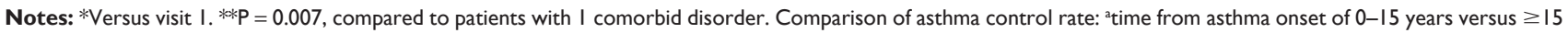
years at visit I: $P=0.692$; and at visit $4: P=0.1643$. ${ }^{\circ} B M I$ of $\geq 30 \mathrm{~kg} / \mathrm{m}^{2}$ versus $<30 \mathrm{~kg} / \mathrm{m}^{2}$ at visit $\mathrm{I}: P=0.526$; and at visit $4: P=0.009$. ${ }^{\mathrm{c}}$ smokers versus non-smokers at visit I: $P=0.010$; and at visit 4: $P=0.030$.

Abbreviations: ACT, asthma control test; BMI, body mass index; n, number; SD, standard deviation; $\vee$, visits. 
Table 3 Asthma control level according to inhaler device as assessed by the physicians

\begin{tabular}{|c|c|c|c|c|c|c|c|}
\hline & \multirow{3}{*}{$\begin{array}{l}\text { Total } \\
(n=572)\end{array}$} & \multirow{2}{*}{\multicolumn{2}{|c|}{$\frac{\text { Visit I (Month } 0 \text { ) }}{\text { Asthma control status }}$}} & \multirow{3}{*}{$\begin{array}{l}\text { Total } \\
(n=308)\end{array}$} & \multirow{2}{*}{\multicolumn{2}{|c|}{$\begin{array}{l}\text { Visit } 4 \text { (Month 6) } \\
\text { Asthma control status }\end{array}$}} & \multirow[t]{3}{*}{$P$ value* } \\
\hline & & & & & & & \\
\hline & & $\begin{array}{l}\text { Controlled } \\
(A C T \geq 20, \\
n=352)\end{array}$ & $\begin{array}{l}\text { Uncontrolled } \\
(A C T<20, \\
n=220)\end{array}$ & & $\begin{array}{l}\text { Controlled } \\
(A C T \geq 20, \\
n=269)\end{array}$ & $\begin{array}{l}\text { Uncontrolled } \\
(A C T<20, \\
n=39)\end{array}$ & \\
\hline \multicolumn{8}{|c|}{ According to inhaler types used } \\
\hline Fixed dose combinations & n (\%) & & & & & & \\
\hline FP/S Discus & $152(26.6)$ & $94(61.8)$ & $58(38.2)$ & $79(25.6)$ & $70(88.6)$ & $9(I I .4)$ & $<0.001$ \\
\hline BDP/F Solution spray & $107(18.7)$ & $72(67.3)$ & $35(32.7)$ & $60(19.5)$ & $54(90.0)$ & $6(10.0)$ & $<0.001$ \\
\hline B/F Turbuhaler & $156(27.3)$ & $91(58.3)$ & $65(41.7)$ & $87(28.2)$ & $74(85.1)$ & $13(14.9)$ & $<0.001$ \\
\hline Separate combinations & n (\%) & & & & & & \\
\hline B + F Aerolizer & $84(14.7)$ & $48(57.1)$ & $36(42.9)$ & $51(16.6)$ & $39(76.5)$ & $12(23.5)$ & 0.131 \\
\hline $\mathrm{B}+\mathrm{F}$ Easyhaler** & $21(3.8)$ & $14(66.7)$ & $7(33.3)$ & $8(2.6)$ & $8(100.0)$ & $0(0.0)$ & $* *$ \\
\hline
\end{tabular}

Notes: *Rate of uncontrolled asthma visit I versus visit 4. **No statistical analysis was done because of small number of patients.

Abbreviations: ACT, asthma control test; B, budesonide; BDP, beclometasone dipropionate; $F$, formoterol; FP, fluticasone propionate; S, salmeterol; $n$, number.

reported suffering symptoms more than once a week was $24 \%$ and $32 \%$, respectively. ${ }^{29}$ In a population-based screening conducted in eleven European countries within the scope of European Respiratory Health Survey (ERCHS) II, overall asthma control rate was reported to be $32 \%$, while the proportion of uncontrolled asthma in ICS users greatly varied by country, ranging from $20 \%$ (Iceland) to $67 \%$ (Italy). ${ }^{19}$ Recently, a survey conducted in five European countries indicated that $50.4 \%$ of asthmatics had low levels of control; $; 3$ this percentage increased to $56.6 \%$ in a more recent survey conducted in the same countries. ${ }^{31}$

A cross-sectional study of 1188 patients with asthma from 28 centers in Turkey indicated controlled asthma in 51.5\% of the patients $(\mathrm{ACT} \geq 20),{ }^{9}$ while the Asthma Insights and

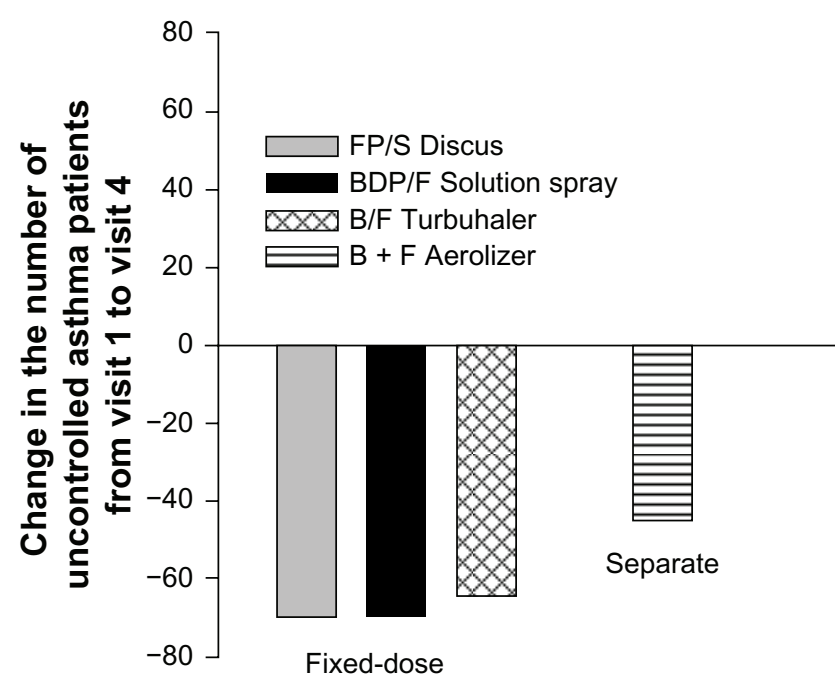

Figure 2 Change in percentage of uncontrolled asthma patients $(n=220)$ with fixed dose and seperate combination inhaler treatments from visit I to visit 4 . Abbreviations: FP/S, fluticasone propionate/salmeterol; BDP/F, beclomethasone/ formoterol; B/F, budesonide/formoterol; B + F, budesonide + formoterol.
Reality in Turkey (AIRET) study, ${ }^{8}$ consistent with other international AIR surveys, demonstrated achievement of guideline-based asthma control in only $1.3 \%$ of participants, despite the availability of effective therapies.

The inconsistency of data on asthma control has been associated with the varied implementations of the asthma treatment guidelines in different countries, different treatment regimens, and geographic variation in asthma severity. ${ }^{19}$ Moreover, comparison of data from different studies is difficult due to different asthma control measures and data collection methods adopted. For example, the higher proportion of controlled patients in our study compared to the ECRHS II survey ${ }^{19}$ may be linked to the fact that in the latter, asthma control was evaluated with the GINA guidelines composite measure, including lung function, whereas the former used ACT, which excludes lung function; therefore a higher rate of asthma control is to be expected. ${ }^{15}$

The combined effects of failure to comply with recommendations and poor patient adherence to treatment, along with low usage of preventive medicine and low expectations of treatment, can be considered as the leading causes of poor

Table 4 Logistic regression analysis for predictors of asthma control

\begin{tabular}{llll}
\hline & OR & $\mathbf{9 5 \%} \mathbf{C l}$ & $\boldsymbol{P}$ value \\
\hline Female & $\mathrm{I} .35 \mathrm{I}$ & $0.876 ; 2.085$ & 0.173 \\
Asthma related comorbidity present & 0.602 & $0.419 ; 0.863$ & 0.006 \\
Asthma unrelated comorbidity present & 0.926 & $0.624 ; 1.373$ & 0.700 \\
Smoking & 0.522 & $0.330 ; 0.825$ & 0.005 \\
Patient age $>60$ years & 1.456 & $0.735 ; 2.883$ & $0.28 \mathrm{I}$ \\
$\mathrm{BMI} \geq 30 \mathrm{~kg} / \mathrm{m}^{2}$ & 0.926 & $0.628 ; 1.367$ & 0.700 \\
Disease duration $\geq 10$ years & $\mathrm{I} .070$ & $0.710 ; 1.612$ & 0.748 \\
Educated (literate) & 0.533 & $0.229 ; 1.238$ & 0.143 \\
\hline
\end{tabular}

Abbreviations: $\mathrm{BMI}$, body mass index; $\mathrm{Cl}$, confidence interval; OR, odds ratio. 
disease control. ${ }^{32}$ Given the positive influence of close patient monitoring on asthma control rates in our study, we consider better implementation of asthma management guidelines and patient education to raise awareness and expectations as crucial to improving asthma outcomes in Turkey. ${ }^{8}$

The majority (79.5\%) of patients with persistent asthma in our study were receiving fixed combination therapy. SABA was used in $32.5 \%$, ICS in $20.3 \%$, and LABA in $13.6 \%$ of patients, while spray (31.5\%), turbuhaler $(29.9 \%)$ and discus (26.6\%) were the most frequently used inhaler types, with a high level ( $>94 \%)$ of overall satisfaction from inhaler therapy. Likewise, data from a past study concerning determinants of asthma control at tertiary healthcare level in Turkey indicated use of ICS and LABA combination in 57\% of the 900 patients surveyed. ${ }^{9}$

The use of fixed combination therapy in the majority of our patients is consistent with the remarkable alteration in practice patterns of asthma management in the last decade. There has been an increase in the prescription rate of controller medications, including multiple controllers for ICS + LABA, after Asthma Insights and Reality (AIR) surveys in the US, Europe, Asia-Pacific, Japan and Latin America populations reported low levels of asthma control..$^{24,33-36}$

Our findings found asthma control to be negatively associated with the incidence of comorbidities such as rhinitis, sinusitis and GERD, while it was positively associated with the use of fixed dose combination treatments. Significantly higher rates of asthma control were achieved by visit 4 compared to visit 1 , even in patients with $\geq 15$ years of asthma duration, and irrespective of age, gender, asthma duration, smoking status or BMI. However the presence of asthmarelated comorbidity and active smoking were found to be significant predictors of worse asthma control.

ICS/LABA fixed combinations are reportedly the most commonly used anti-asthmatic medications ${ }^{15}$ and the most effective treatment choice. ${ }^{15,32}$ Our findings confirmed this, with $61.5 \%$ of patients using fixed dose combination treatment achieving asthma control.

Indeed, the use of fixed dose combination therapy (ICS/ LABA) was among the factors associated with optimal control of asthma in a study from France, ${ }^{37}$ along with normal BMI, non-smoker status, age $<50$ and good compliance. On the other hand, exacerbation, use of reliever medication, switch of therapy and smoking have been listed as the factors for poor control in a Swiss study. ${ }^{38}$ In another study from France, lack of asthma control in $41.1 \%$ of 4362 patients with persistent asthma was associated with patient-related factors including smoking, poor compliance and critical errors in device manipulation. ${ }^{39}$
Our study is also in line with the international populationbased ECRHS II Survey conducted in 11 countries, ${ }^{19}$ which reported no differences based on gender or age in categories of asthma control.

Asthma-related comorbidities were identified in $56.1 \%$ of patients overall in our study population, with rhinitis in $38.3 \%$, GERD in $18.5 \%$ and sinusitis in $18.4 \%$. This is in accordance with the most common comorbidities reported in asthma, including rhinitis, sinusitis, GERD, obstructive sleep apnea, hormonal disorders and psychiatric disorders. ${ }^{40}$ Our findings that higher scores of ACT and higher likelihood of asthma control were linked with a lesser number of comorbidities, support the evidence that various comorbid conditions such as rhino-sinusitis, GERD, psychological disturbances, and respiratory infections, are often observed in asthmatic patients ${ }^{40}$ and will place greater burden on healthcare systems unless taken into consideration in asthma treatment. ${ }^{41}$

In accordance with the data ${ }^{31}$ that indicate smoking is a critical factor in the risk of poor asthma control ${ }^{42,43}$ and impaired corticosteroid response, ${ }^{44}$ there was a significantly lower percentage of smokers classified under the controlled asthma category at visit 1 (51.0\% versus $64.0 \%$ non-smokers, $P=0.010)$ and visit $4(78.0 \%$ versus $89 \%$ non-smokers, $P=0.030)$ in our study population.

Our study's greatest value is in being the first large-scale, detailed survey conducted across Turkey using a patient evaluation questionnaire. The limitations are the lack of data on asthma severity and also the high drop-out rate (46.0\%) from visit 1 to visit 4 .

\section{Conclusion}

In conclusion, our findings in this real-life prospective ASIT study revealed an asthma control rate of $61.5 \%$ in adult outpatients with persistent asthma in Turkey, which increased upon each follow-up, regardless of the smoking, educational and employment status of the patients. Fixed dose combinations proved superior in the achievement of asthma control. However, poor asthma control was associated with the incidence of comorbid diseases. Our findings have provided valuable data on the positive role of regular monitoring in disease control. We therefore advocate regular patient monitoring and patient education to raise awareness and therapeutic expectations, in order to better implement asthma management guidelines and achieve better control of the disease.

\section{Acknowledgments}

This study is funded by Chiesi İlac Tic. A.S. Turkiye. We would like to thank KAPPA Consultancy Training Research 
Ltd, Istanbul, for providing editorial support; Monitor CRO, Istanbul, for providing support in statistical analysis; and Aysegul Kahraman from Chiesi Tic. A.S. Turkiye for her great efforts and contributions at all stages of the study publication. The author wrote this paper on behalf of the ASIT Study Group. The other members, (by the physician's name in descending order of number of patients enrolled) are:

1. Yıldız F, Study Coordinator (Department of Pulmonary Diseases, Kocaeli University School of Medicine, Kocaeli)

2. Erbagci A (Zonguldak Uzun Mehmet Chest Diseases Hospital, Zonguldak)

3. Demirel YS (Department of Chest Diseases, Ankara University, School of Medicine, Ankara)

4. Akcalı SD (Chest Diseases Clinic, Ankara Diskapı Yıldırım Beyazıt Hospital, Ankara)

5. Ekici A (Department of Chest Diseases, Kirikkale University, School of Medicine, Kirikkale)

6. Dursunoglu N (Department of Chest Diseases,Pamukkale University School of Medicine,Denizli)

7. Ediger D (Department of Chest Diseases, Uludag University, School of Medicine, Bursa)

8. Erdinc M (Department of Chest Diseases, Ege University, School of Medicine, Izmir)

9. Cemri SC (Chest Diseases Clinic, Mersin State Hospital, Mersin)

10. Kalyoncu AF (Department of Chest Diseases, Hacettepe University, School of Medicine, Ankara)

11. Guclu SZ (Dr. Suat Seren Chest Diseases Hospital, Izmir)

12. Aktogu S (Dr. Suat Seren Chest Diseases Hospital, Izmir)

13. Bayramgurler B (Chest Diseases Clinic, Derince Research and Training Hospital, Kocaeli)

14. Bayram M (Chest Diseases Clinic, Sivas Numune Research and Training Hospital, Sivas)

15. Akgun M (Department of Chest Diseases, Erzurum Atatürk University, School of Medicine, Erzurum)

16. Mirici A (Department of Chest Diseases, Canakkale 18 March University, School of Medicine, Canakkale)

17. Akyildiz L (Chest Diseases Clinic, Private Park Hospital, Mardin)

18. Celik P (Department of Chest Diseases, Celal Bayar University, School of Medicine, Manisa)

19. Guven AO (Nihat Kitapci Chest Diseases Hospital, Erzurum)

20. Camsari G (Yedikule Chest Diseases Hospital, Istanbul)
21. Ozseker F (Sureyyapasa Chest Diseases Hospital, Istanbul)

22. Cimen F (Atatürk Chest Diseases Hospital, Ankara)

23. Kurutepe M (Sureyyapasa Chest Diseases Hospital, Istanbul)

24. Senyigit A (Department of Chest Diseases, Dicle University, School of Medicine, Diyarbakir)

25. Bektas Y (Trabzon Chest Diseases Hospital, Trabzon)

26. Ozbudak O (Department of Chest Diseases, Akdeniz University, School of Medicine, Antalya)

27. Saylan B, Baslilar S (Chest Diseases Clinic, Umraniye Research and Training Hospital, Istanbul)

28. Polatli M (Department of Chest Diseases, Adnan Menderes University, School of Medicine, Aydin)

29. Cagatay T (Department of Chest Diseases, Istanbul University, Istanbul School of Medicine, Istanbul)

30. Kalkan S (Chest Diseases Clinic, Private Batman Hospital, Batman)

31. Ozer A (Chest Disease Clinic, Cukurova State Hospital, Adana).

\section{Disclosure}

The author declares no conflict of interests in this paper.

\section{References}

1. European Community Respiratory Health Survey. Variations in the prevalence of respiratory symptoms, self-reported asthma attacks, and use of asthma medication in the European community respiratory health survey (ECRHS). Eur Respir J. 1996;9:687-696.

2. Van Ganse E, Antonicelli L, Zhang Q, et al. Asthma-related resource use and cost by GINA classification of severity in three European countries. Respir Med. 2006;100:140-147.

3. Masoli M, Fabian D, Holt S, Beasley R. The global burden of asthma: executive summary of the GINA Dissemination Committee report. Allergy. 2004;59:469-478.

4. Turkish Ministry of Health Chronic Airway Diseases (COPD-Asthma) Prevention and Control Program (2009-2013) Action Plan, Ankara 2009:39-41.

5. Global initiative for asthma (GINA). Global strategy for asthma management and prevention. NHLBI/WHO workshop report. 1995, updated 2007.

6. Bateman ED, Boushey HA, Bousquet J, et al. Can guideline-defined asthma control be achieved? The Gaining Optimal Asthma Control study. Am J Respir Crit Care Med. 2004;170:836-844.

7. Rabe KF, Adachi M, Lai CK, et al. Worldwide severity and control of asthma in children and adults: the global asthma insights and reality surveys. J Allergy Clin Immunol. 2004;114:40-47.

8. Sekerel BE, Gemicioglu B, Soriano JB. Asthma insights and reality in Turkey (AIRET) study. Respir Med. 2006;100:1850-1854.

9. Turktas H, Mungan D, Uysal MA, Oguzulgen K; Turkish Asthma Control Survey Study Group. Determinants of asthma control in tertiary level in Turkey: a cross-sectional multicenter survey. J Asthma. 2010;47: 557-562.

10. Expert Panel Report 2 Guidelines for the diagnosis and management of asthma. Publication No 97-4051. Bethesda: National Heart, Lung and Blood Institutes of Health, 1997. 
11. Lundback B, Dahl R. Assessment of asthma control and its impact on optimal treatment strategy. Allergy. 2007;62:611-619.

12. GINA (Global Initiative on Asthma), National Institutes of Health, National Heart Lung and Blood Institute, NHLBI/WHO Workshop Report. Global strategy for asthma management and prevention. Jan 1995, updated 2008.

13. National Asthma Education and Prevention Program. Expert Panel Report 3 (EPR-3): guidelines for the Diagnosis and Management of Asthma-Summary Report 2007. J Allergy Clin Immunol. 2007;120: 94-138. Erratum in: J Allergy Clin Immunol. 2008;121:1330.

14. Ohta K, Yamaguchi M, Akiyama K, et al. Japanese guideline for adult asthma. Allergol Int. 2011;60:115-145.

15. Allegra L, Cremonesi G, Girbino G, et al; PRISMA (PRospectIve Study on asthMA control) Study Group. Real-life prospective study on asthma control in Italy: cross-sectional phase results. Respir Med. 2012;106:205-214.

16. Horne R, Price D, Cleland J, et al. Can asthma control be improved by understanding the patient's perspective? BMC Pulm Med. 2007;7:8.

17. Rank M, Wollan P, Li J, Yawn B. Trigger recognition and management in poorly controlled asthmatics. Allergy Asthma Proc. 2010;31: 99-105.

18. Global initiative for asthma (GINA). Global strategy for asthma management and prevention. Updated 2011. Available from: http://www. ginasthma.org/uploads/users/files/GINA_Report2011_May4.pdf. Accessed November 14, 2012.

19. Cazzoletti L, Marcon A, Janson C, et al; Therapy and Health Economics Group of the European Community Respiratory Health Survey. Asthma control in Europe: a real-world evaluation based on an international population-based study. J Allergy Clin Immunol. 2007;120: 1360-1367.

20. Nathan RA, Sorkness CA, Kosinski M, et al. Development of the asthma control test: a survey for assessing asthma control. J Allergy Clin Immunol. 2004;113:59-65.

21. Schatz M, Sorkness CA, Li JT, et al. Asthma Control Test: reliability, validity, and responsiveness in patients not previously followed by asthma specialists. J Allergy Clin Immunol. 2006;117: 549-556.

22. Ko FW, Hui DS, Leung TF, et al. Evaluation of the asthma control test: a reliable determinant of disease stability and a predictor of future exacerbations. Respirology. 2012;17:370-378.

23. MAPI Research Institute: Linguistic validation. [Webpage on the internet]. Lyon: MAPI Research Institute; 2004. http://www.mapiresearch. fr/i 02intr.htm. Accessed February 11, 2010.

24. Rabe KF, Vermeire PA, Soriano JB, Maier WC. Clinical management of asthma in 1999: the Asthma Insights and Reality in Europe (AIRE) study. Eur Respir J. 2000;16:802-807.

25. Vermeire PA, Rabe KF, Soriano JB, Maier WC. Asthma control and differences in management practices across seven European countries. Respir Med. 2002;96:142-149.

26. Soriano JB, Rabe KF, Vermeire PA. Predictors of poor asthma control in European adults. J Asthma. 2003;40:803-813.

27. Chapman KR. Impact of 'mild' asthma on health outcomes: findings of a systematic search of the literature. Respir Med. 2005;99:1350-1362.
28. Haselkorn T, Fish JE, Zeiger RS, et al; TENOR Study Group. Consistently very poorly controlled asthma, as defined by the impairment domain of the Expert Panel Report 3 guidelines, increases risk for future severe asthma exacerbations in The Epidemiology and Natural History of Asthma: Outcomes and Treatment Regimens (TENOR) study. J Allergy Clin Immunol. 2009;124:895-902.

29. Lopez-Vina A, Cimas JE, Diaz Sanchez C, Coria G, Vegazo O, Picado Valles C. A comparison of primary care physicians and pneumologists in the management of asthma in Spain: ASES study. Respir Med. 2003;97:872-881.

30. Demoly P, Paggiaro P, Plaza V, et al. Prevalence of asthma control among adults in France, Germany, Italy, Spain and the UK. Eur Respir Rev. 2009; 18:105-112.

31. Demoly P, Gueron B, Annunziata K, Adamek L, Walters RD. Update on asthma control in five European countries: results of a 2008 survey. Eur Respir Rev. 2010;19:150-157.

32. Fueyo A, Ruiz MA, Ancochea J, Guilera M, Badia X; ESCASE Group. Asthma control in Spain. Do season and treatment pattern matter? The ESCASE study. Respir Med. 2007;101:919-924.

33. Lai CK, De Guia TS, Kim YY, et al. Asthma Insights and Reality in Asia-Pacific Steering Committee. Asthma control in the Asia-Pacific region: the asthma insights and reality in Asia-Pacific study. J Allergy Clin Immunol. 2003;111:263-268.

34. Adams RJ, Fuhlbrigge A, Guilbert T, Lazano P, Martinez F. Inadequate use of asthma medication in the United States: results of Asthma in America national population survey. JAllergy Clin Immunol. 2002;110: $58-64$.

35. Adachi M, Morikawa A, Ishihara K. Asthma insights and reality in Japan (AIRJ). Arerugi. 2002;51:411-420.

36. Neffen H, Fritscher C, Schacht FC, et al; AIRLA Survey Group. The Asthma insights and reality in Latin America survey. Rev Panam Salud Publica. 2005;17:191-197.

37. Godard P, Huas D, Sohier B, Pribil C, Boucot I. Asthma control in general practice: a cross-sectional survey of 16,580 patients. Presse Med. 2005;34:1351-1357. French [with English abstract].

38. Miedinger D, Neukomm E, Chhajed PN, et al. The use of the Asthma Control Test in general practice and its correlation with asthma control according to the GINA guidelines. Curr Med Res Opin. 2011;27: 2301-2308.

39. Molimard M, Le Gros V. Impact of patient-related factors on asthma control. J Asthma. 2008;45:109-113.

40. Boulet LP, Boulay MÈ. Asthma-related comorbidities. Expert Rev Respir Med. 2011;5:377-393.

41. Gershon AS, Wang C, Guan J, To T. Burden of comorbidity in individuals with asthma. Thorax. 2010;65:612-618.

42. McLeish AC, Zvolensky MJ. Asthma and cigarette smoking: a review of the empirical literature. JAsthma. 2010;47:345-361.

43. Haughney J, Price D, Kaplan A, et al. Achieving asthma control in practice: understanding the reasons for poor control. Respir Med. 2008;102:1681-1693.

44. Thomson NC, Chaudhuri R. Asthma in smokers: challenges and opportunities. Curr Opin Pulm Med. 2009;15:39-45.

Journal of Asthma and Allergy

\section{Publish your work in this journal}

The Journal of Asthma and Allergy is an international, peer-reviewed open-access journal publishing original research, reports, editorials and commentaries on the following topics: Asthma; Pulmonary physiology; Asthma related clinical health; Clinical immunology and the immunological basis of disease; Pharmacological interventions and

new therapies. Issues of patient safety and quality of care will also be considered. The manuscript management system is completely online and includes a very quick and fair peer-review system, which is all easy to use. Visit http://www.dovepress.com/testimonials.php to read real quotes from published authors. 